\title{
On optimality conditions for robust weak sharp solution in uncertain optimizations
}

\section{JutAmas KeRDKAEW ${ }^{1}$, RABIAn WANGKEEREE*,1,2 and Gue MYUnG LEE ${ }^{3}$}

\begin{abstract}
.
In this paper, we investigate the robust optimization problem involving nonsmooth and nonconvex realvalued functions. We firstly establish a necessary condition for the local robust weak sharp solution of considered problem under a constraint qualification. These optimality conditions are presented in terms of multipliers and Mordukhovich subdifferentials of the related functions. Then, by employing the robust version of the (KKT) condition, and some appropriate generalized convexity conditions, we also obtain some sufficient conditions for the global robust weak sharp solutions of the problem. In addition, some examples are presented for illustrating or supporting the results.
\end{abstract}

Acknowledgment. This research is partially supported by the Science Achivement Scholarship of Thailand and Naresuan university. The third author was supported by the National Research Foundation of Korea (NRF) grant funded by the Korea government (MSIT) (NRF-2017R1E1A1A03069931).

\section{REFERENCES}

[1] Ben-Tal, A., Ghaoui, L. E. and Nemirovski, A., Robust optimization, Princeton series in applied mathematics, Priceton, NJ: Priceton University Press, 2009

[2] Bertsimas, D., Brown, D. and Caramanis, C., Theory and applications of robust optimization, SIAM Rev., 53 (2011), 464-501

[3] Beck, A. and Ben-Tal, A., Duality in robust optimization: primal worst equals dual best, Oper. Res. Lett., 37 (2009), 1-6

[4] Bonnans, J. F. and Shapiro, A., Perturbation Analysis of Optimization Problems, Springer-Verlag, New York, 2000

[5] Burke, J. V., Lewis, A. and Overton, M., Optimization matrix stability, Proc. Am. Math. Soc., 129 (2000), $1635-1642$

[6] Burke, J. V., Lewis, A. and Overton, M., Optimization stability and eigenvalue multiplicity, Found. Comput. Math., 1 (2001), 205-225

[7] Burke, J. V. and Ferris, M. C., Weak sharp minima in mathematical programming, SIAM J. Control Optim., 36 (1993), 1340-1359

[8] Burke, J. V. and Deng, S., Weak sharp minima revisited, part I: Basic theory, Control Cybern., 31 (2002), 439-469

[9] Burke, J. V. and Deng, S., Weak sharp minima revisited, part II: Application to linear regularity and error bounds, Math. Program., Ser. B, 104 (2005), 235-261

[10] Burke, J. V. and Deng, S., Weak sharp minima revisited, part III: Error bounds for differentiable convex inclusions, Math. Program., Ser. B, 116 (2009), 37-56

Received: 26.10.2019; In revised form: 02.03.2020; Accepted: 09.03.2020

2010 Mathematics Subject Classification. 90C25, 90C46, 49K99.

Key words and phrases. Uncertain optimization, robust weak sharp solution, optimality conditions, Mordukhovich generalized differentiation.

Corresponding author: Rabian Wangkeeree; rabianw@nu.ac.th 
[11] Chuong, T. D., Optimality and duality for robust multiobjective optimization problem, Nonlinear Analysis., 134 (2016), 127-143

[12] Chuong, T. D. and Kim, D. S., Optimality conditions and duality in nonsmooth multiobjective optimization problems, Ann Oper Res., 217 (2014), 117-136

[13] Ferris, M. C., Weak sharp minima and penalty functions in mathematical programming, Ph.D. thesis, Universiy of Cambridge, Cambridge, UK, 1988

[14] Jeyakumar, V. and Li, G., Characterizing robust set containments and solutions of uncertain linear programs without qualifications, Oper. Res. Lett., 38 (2010), 188-194

[15] Jeyakumar, V., Li, G. Y. and Lee, G. M., Robust duality for generalized convex programming problems under data uncertainty, Nonlinear Anal., 75 (2012), No. 3, 1362-1373

[16] Jeyakumar, V., Lee, G. M. and Li, G., Characterizing robust solution sets of convex programs under data uncertainty, J. Optim Theory., 164 (2015), 407-435

[17] Kerdkaew, J. and Wangkeeree, R., Characterizing robust weak sharp solution sets of uncertain convex optimizations, Journal of Industrial and Management Optimization, doi: 10.3934/jimo.2019074 (2019)

[18] Lewis, A. S. and Pang, J. S., Error bounds for convex inequality systems, In: Crouzeix, J. P. (ed.) Proceedings of the Fifth Symposium on Generalized Convexity, Luminy-Marseille, 1996

[19] Mordukhovich, B. S., Variational Analysis and Generalized Differentiation. I: Basic Theory, Springer, Berlin, 2006

[20] Polyak, B .T., Sharp Minima, Institute of Control Sciences Lecture Notes, Moscow, USSR, 1979; Presented at the IIASA Workshop on Generalized Lagrangians and Their Applications, IIASA, Laxenburg, Austria, 1979

[21] Rockafellar, R. T. and Wets, R. J.-B., Variational Analysis, Springer, Berlin, 1998

[22] Sun, X.-K., Peng, Z.-Y. and Guo, X.-L., Some characterizations of robust optimal solutionsfor uncertain convex optimization problems, Optim. Lett., 10 (2016), No. 7, 1463-1478

[23] Sun,X.-K., Long, X.-K., Fu, H.-Y. and Li, X.-B., Some characterizations of robust optimal solutions for uncertain fractional optimization and applications, J. Ind. Manag. Optim., 13 (2017), No. 2, 803-824

[24] Sun, X.-K., Teo, K. L. and Tang, L., Dual approaches to characterize robust optimal solution sets for a class of uncertain optimization problems, J. Optim. Theory Appl., 182 (2019), No. 3, 984-1000

[25] Zheng, X. Y. and Ng, K. F., Strong KKT conditions and weak sharp minima in convex-composite optimization, Math. Program., 126 (2009), 259-279

[26] Zheng, X. Y. and Yang, X. Q., Weak sharp minima for semi-infinite optimization problems with applications, SIAM J. Optim., 18 (2004), 573-588

[27] Zhu, S. K., Weak sharp efficiency in multiobjective optimization, Optim. Lett., 10 (2016), 1287-1301

${ }^{1}$ Department of Mathematics

NARESUAN UNIVERSITY

FACULTY OF SCIENCE

PHITSANULOK, 65000, THAILAND

Email address: jutamas.jk85@mail.com

${ }^{2}$ NARESUAN UNIVERSITY

RESEARCH CENTER FOR ACADEMIC EXCELlENCE IN MATHEMATICS

PHITSANULOK, 65000, THAILAND

Email address: rabianwenu.ac.th

${ }^{3}$ Department of Applied Mathematics

PUKYONG NATIONAL UNIVERSITY

FACULTY OF SCIENCE

BusAn, 48513, REPUBlic OF KorEA

Email address: gmlee@pknu.ac.kr 